\title{
Tennis players comprehensive ability evaluation
}

\author{
Feng Li a , Qian Yang, Bing Zhang ${ }^{b}$ \\ Institute of Physical Education, Huanggang Normal University, Huangzhou 438000, China
}

\begin{abstract}
Tennis player's ability to show there are a lot of uncertainty, in order to make evaluation of athletes, through the fuzzy comprehensive evaluation model, analyze the tennis player ability performance, considering in tennis field technology, competition consciousness, physical quality, psychological quality four aspects, field evaluation model, and through the model obtained tennis player scores change section. Although the result is not accurate results, but you can get a precise range, comprehensive multi-factor, solving the change of the section performance athletes, and then selected and analysis was carried out on the tennis player.
\end{abstract}

\section{Introduction}

Tennis is a turn-based competition. In 1885 , tennis was first introduced into China. Until 2003, Chinese tennis was on track and thrived, especially women's tennis received a lot of wonderful scores. For China, there is a lot of room for improvement. Every country's scholar has studied tennis. Forsyth and Schlenkey choose 122 tennis players in a random way and investigate. Later they say that the loser spare less effort than the winner and other factors of different aspects, especially women always think their failures are due to themselves, not due to the luck. Qiu Yijun analyzes the psychological factors of the tennis and comes to the conclusion that the psychological factors in the tennis competition are the major point of getting success [1-3]. Because of the less of reification and explicitation and less of the research based on the complicated psychological factors, Wang Fang put forward the feature of the specific technique of tennis and the evaluation system. $\mathrm{He}$ gets his weight based on the experts and some experiences. It's very objective. Wang $\mathrm{Ni}$ makes the evaluation model of the tennis specific performance based on the neural networks, and she uses the method of multiple linear regression to forecast the tennis score [4-7]. Besides she shows the exact program to promote the quality levels of the tennis players. Yin Hang shows the research and analysis of physical fitness, body physique towards different ranks of the tennis players. Mark and others choose 59 as the target and the results show that the players with different scores don't have apparent difference, but other successful people think it is because of the stability and controllability [8]. In this passage we use the comprehensive assessment of fuzzy mathematics to analyze the tennis players' performances and we mainly consider the game technical of the player in the field which includes the game technical, competition consciousness, physical quality and psychological quality. We hope that this can be the reference for the tennis player, coach and researchers of tennis.

\section{Establishment of the model}

After getting the changing model of the fuzzy comprehensive assessment, we can set up the transitional function of all kinds of corresponding factor assessments in different levels. The subordinate function of factor $u 1, u 2$, $\mathrm{u} 3, \mathrm{u} 4$, and $\mathrm{u} 5$ can be shown as follow:

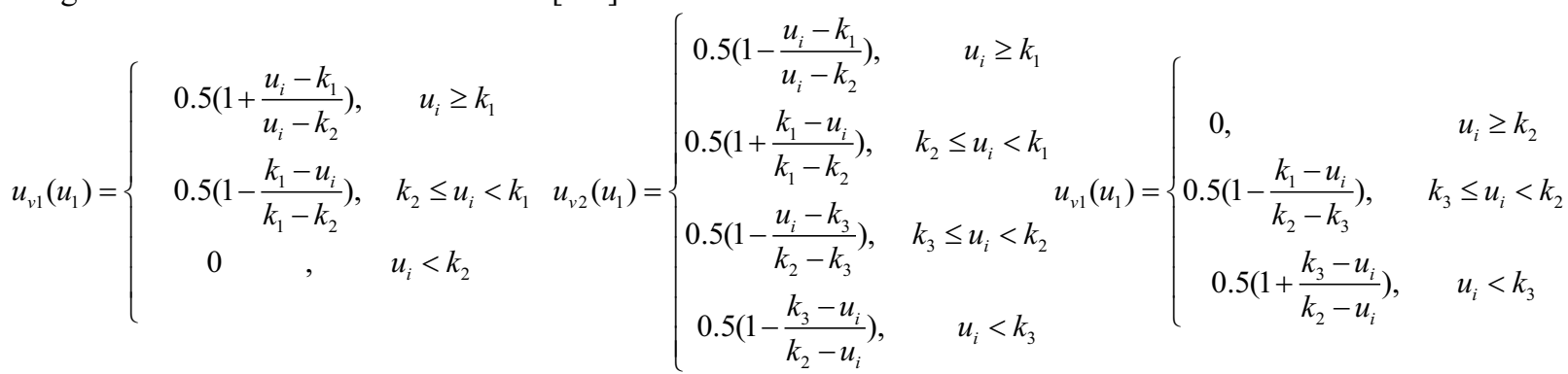

According to the distribution of the court, the text takes competition spirit into consideration and draws a conclusion that competition spirit is needed to control the game to a player, as shown in Fig.1.

a,b Corresponding author: tiyuxi@qq.com 


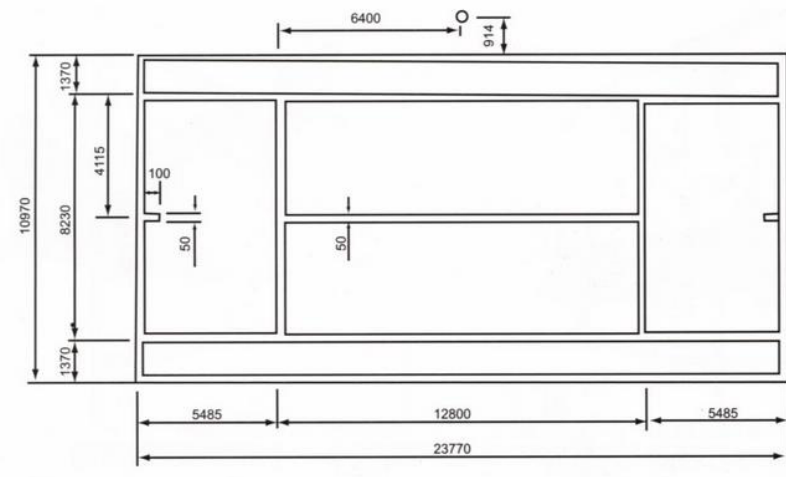

Figure1. Distribution of the court

To set up the factor set $\mathrm{U}$ and $\mathrm{U}=(\mathrm{U} 1 \mathrm{U} 2 \mathrm{U} 3 \mathrm{U} 4)$. U1 is the technique. $\mathrm{U} 2$ is the competition spirit. $\mathrm{U} 3$ is the physical quality and U4 is the mental quality. Then we can make Table1.

By collecting statistics and analyzing, we can sort the four factors by the degree of importance, as shown in Table 2 .

Table 1. The evaluation system of tennis players.

\begin{tabular}{|c|c|c|c|}
\hline $\begin{array}{c}\text { Technique } U_{1} 0 . \\
35\end{array}$ & $\begin{array}{c}\text { Competitio } \\
\mathrm{n} \\
\text { spirit } U_{2} 0.3\end{array}$ & $\begin{array}{c}\text { Physical } \\
\text { quality } U_{3} 0 . \\
2\end{array}$ & $\begin{array}{c}\text { Mental } \\
\text { quality } U_{4} 0.15\end{array}$ \\
\hline $\begin{array}{c}\text { Hitting the } \\
\text { ball } u_{11}\end{array}$ & Tactics $u_{21}$ & $\begin{array}{c}\text { Stamina } \\
u_{31}\end{array}$ & $\begin{array}{c}\text { Concentration } \\
u_{41}\end{array}$ \\
\hline Receiving $u_{12}$ & $\begin{array}{c}\text { Discretion } \\
u_{22}\end{array}$ & Speed $u_{32}$ & $\begin{array}{c}\text { Confidence } \\
u_{42}\end{array}$ \\
\hline Serve $u_{13}$ & $\begin{array}{c}\text { Response } \\
u_{23}\end{array}$ & $\begin{array}{c}\text { Physical } \\
\text { strength } \\
u_{33}\end{array}$ & $\begin{array}{c}\text { Personal } \\
\text { quality } u_{43}\end{array}$ \\
\hline Volley $u_{14}$ & $\begin{array}{c}\text { Competitio } \\
\mathrm{n}\end{array}$ & Sensitivity & \\
& $u_{24}$ & $u_{34}$ & \\
\hline Footwork $u_{15}$ & & & \\
\hline
\end{tabular}

Table 2. The order of the four factors by the degree of importance

\begin{tabular}{|c|c|c|c|c|}
\hline Classification & Order1 & Order2 & Order3 & Order4 \\
\hline $\begin{array}{c}\text { Competition } \\
\text { spirit } U_{1}\end{array}$ & 23 & 7 & 4 & 0 \\
\hline Technique $U_{2}$ & 7 & 18 & 8 & 0 \\
\hline Mental quality $U_{3}$ & 0 & 9 & 13 & 12 \\
\hline Physical quality $U_{4}$ & 3 & 0 & 9 & 21 \\
\hline
\end{tabular}

Through the evaluation of every indexes of a tennis player, we can get Table 3 .

Through table 4 Evaluation and membership, we can get the evaluation set of technique, field consciousness, physical fitness and mental fitness. Normalization $B_{i}$, we can get the second stage of fuzzy evaluation matrix.
Table 3. Evaluation value of every indexes of a tennis player.

\begin{tabular}{|c|c|c|c|}
\hline Indexes & $\begin{array}{c}\text { Evaluation } \\
\text { value }\end{array}$ & Indexes & $\begin{array}{c}\text { Evaluation } \\
\text { value }\end{array}$ \\
\hline Strike $u_{11}$ & Very good & Stamina $u_{31}$ & Very good \\
\hline Receive $u_{12}$ & Very good & Speed $u_{32}$ & Good \\
\hline Serve $u_{13}$ & Ordinary & Strength $u_{33}$ & Good \\
\hline Volley $u_{14}$ & Ordinary & Sensitivity $u_{34}$ & Ordinary \\
\hline $\begin{array}{c}\text { Basic footwork } \\
u_{15}\end{array}$ & Ordinary & Fixation $u_{41}$ & Good \\
\hline $\begin{array}{c}\text { Tactics } u_{21} \\
\text { Judgment } u_{22}\end{array}$ & Very good & $\begin{array}{c}\text { Confidence } \\
\text { degree } u_{42}\end{array}$ & Very good \\
\hline $\begin{array}{c}\text { Ability of react } \\
u_{23}\end{array}$ & Very good & Self-diathesis & ordinary \\
\hline $\begin{array}{c}\text { Competition } \\
\text { experience } \\
u_{24}\end{array}$ & Good & & \\
\hline \multicolumn{2}{|l}{} & & \\
\hline
\end{tabular}

$$
\begin{aligned}
& \bar{B}=\left(\begin{array}{l}
B_{1} \\
B_{2} \\
B_{3} \\
B_{4}
\end{array}\right)=\left(\begin{array}{cccc}
0.07 & 0.27 & 0.13 & 0.53 \\
0 & 0.1 & 0.4 & 0.5 \\
0.08 & 0.46 & 0.38 & 0.08 \\
0.14 & 0.2 & 0.3 & 0.36
\end{array}\right) \\
& Z=U^{*} \cdot B=\left(\begin{array}{llll}
0.15 & 0.26 & 0.29 & 0.36
\end{array}\right)
\end{aligned}
$$

On account of $0.36>0.29>0.26>0.15$, the tennis player get the excellent goal, and by comprehensive fuzzy evaluation, the point interval setting is in 90-100.

\section{Conclusions}

Because of sports including tennis contain great inconclusive result, this essay built the mathematic model of comprehensive fuzzy evaluation [9], and analyzed the performance of the tennis players. We mainly considered the technique, field consciousness, physical fitness and mental fitness of the players during the tennis playing. And we get the evaluation matrix by the model to figure out the grade set of the tennis players.

\section{References}

1. I. X. Zhang, Journal of Hubei Sports Science, 21, 74-75, 79 (2002).

2. J. L. Yang et al, Journal of Shandong Physical Education Institute, 18, 51-53 (2002).

3. L. P. Kan, Bulletin of Sport Science \& Technology, 19, 19-20(2011).

4. N. Li and J. D. Zhou, Journal of Jilin Institute of Physical Education, 27, 45-47 (2011).

5. R. E. Kalman, Transaction of the ASME - Journal of Basic Engineering, 82, 35- 45 (1960). 
6. S. Thrun, D. Fox, W. Burgard and F. Dellaert, Artificial Intelligence Journal, 128, 99-141 (2001).

7. X. Wang, Journal of Nanjing Institute of Physical Education, 16, 96-97 (2002).

8. X. Zhang and Q. Zuo, Journal of Coastal Research, 73, 9-16 (2015).
9. G. J. Jiang, H. D Lv and L. Liu, Journal of Mechanical Engineering Research and Developments, 39, 24-29 (2016). 